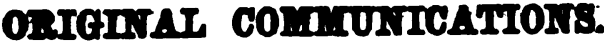

\section{IECTURES ON INSANITY, DELIVERED AT THE BRISTOL MEDICAL SCHOOL DURING THE SUMMER SESSION OF 1855.}

By J. G. DAVEY, M.D.

\section{LECTOBE III.}

82 MONOMANIA. MOBAL INSANITY. NATURE AND PROXIMATE CAUSE OF INSANITY. OCCABIONAL PECULIAB TERMINATION OF INSANITY. ESSENTIAL PATHOLOGY OF INSANITY. VARIBTY OF PATHOLOGICAL CHANGES OBSERVED.

Brope I proceed to the consideration of the nature and proximate cause of insanity, the subject announced to you for to-day, I find it necessary, for the completion of that arrangement I have proposed to myself in this course of lectures, to detain you for a short time whilst I consider the symptomatology of insanity. It is quite necessary that the profession were agreed not only on the terms in use, but on the specific meaning of each of them. I need hardly add, that if so much could be brought about, a basis of operations (to use a Crimean phrase) would be realised, from which much may be expected for psychological medicine.

The words mania, melancholia, monomania, and moral insanity, would seem each of them to convey so definite and precise a meaning, that we may not expect to find them either misapprehended or misapplied. It does, however, not unfrequently happen that to these mere words are atteched meanings which are wanting in fact and truth. Mania, for example, is too commonly understood to mean an active delirium, in which the patient either raves or talls rapidly and incoherently. Incoherence in speech is by some psychologists, looked on as almost the essence of mania. In private practice, you may be long without sufficient opportunities of testing the accuracy of the assertion; but of this you may rest confident, that cases of mania, of the most undoubted and significant character, do occur in which, however active and acute the ideas and feelings may be, however rapid the thoughts of the patient, yet there may be no incoherence. Though the brain may be in a state of increased excitement, it does not follow that this may be unequally distributed. Each and every faculty, emotion, and passion may not unfrequently manifest a palpable and abnormal exaltation of function, a great excess of power; but it does not follow that such a pathological condition is necessarily accompanied with, or indicated by an incoherence of speech. When the volition of the party affected has not succumbed, then does he escape that one indication of mental derangement known by the term incoherence.

The term mania, moreover, is very generally understood to signify only an impaired condition of the understanding. Here, again, we may recognise an error, and a very important one. During the incipient stage of mental disease, it is by no means usual to find the intellectual powers at fault; but, on the other hand, the early indications of insanity are accompanied with a too painful consciousness of the perverted feelings and desires, with the most accurate lnowledge and just appreciation of the irregular and capricious condition of the various emotions and moral qualities of our being; and such, in point of fact, it is which constitute the very essence of mania. I am intimately acquainted with many insane persons who have been indisposed for even years, but who, nevertheless, exhibit no traces of any positive impaiment of the intellect. However much the affections may have become altered from their original and normal condition,-however much the propensities may have become disordered,-not a few among the insane yet preserve the perceptive and reflective faculties intact; and what is more, employ them to much advantage. It is most important that you should bear in mind that the speech and actious of the lunatic must erer be regarded in the light of symptoms of the abnormal condition of his moral nature; for this (not less than his intellectual nature) depends for its healthy manifestations, or otherwise, on the physical condition of the material organ of the mind (brain). In long standing and incurable maniacal disorder you will now and then observe that some one feeling or desire is fastened on the mind of the patient; and that this so predominates in him, as to impart a specific character to the case. Under these circumstances, he will be impelled to intrude the same on your attention, and will seek every opportunity to realise this "feeling" or "desire", whaterer it may be. At length, the judgment will yield its acquiescence, and the reason will succumb to the morbid impression. Then, but not till then, may the intellectual powers bo said to be deranged, and then will arise "delusions", so called. These, as I have elsewhere written, express only the nature of the predominant feelings, and are always in harmony with the morbid affection originating them. For instance, of the primitive mental faculties, those of self-esteem, veneration, or destructiveness, may severally take on diseased action; and their natural functions, in consequence, may at length become so exaggerated, that the sufferer is necessarily the mere instrument of such an unhappy physical condition. Now the first symptom of acute disease, involving the faculties named, is expressed by an extraordinary display of either pride, religious enthusiasm, or anger; if the patient be not relieved, or, which is the same thing, if the abnormal action continue unabated, the chances are that a delusion will become superadded to the other indications of mental derangement, constituting, as it were, a seeming apology for either his ostentatious deportment, or fanaticism, or cruelty of disposition.

Mania, then, must be looked on as primarily a disorder rather of our affections and moral feelings than of the intellectual powers; and of this we may easily satisfy ourselves if we will be at the trouble to look somewhat critically, and as psychologists, into our own acute feelings, and at our individual experiences of man and manners. There are but few of us, though sane, who are not exposed, from time to time, to the causes of acute and painful emotion; in us it is temporary only; but if it were otherwise, if it became persistent, then should we be regarded as insane.

The psychological principle involved in the foregoing remarks is agreeably pourtrayed by Charles Dickens, in his description of Walter's hasty and anxious pursuit of the good and eccentric Captain Cuttle, "uncle Sol's kind friend." The reader of Dombey and Son is told, that as Walter sped along, intent only on the distress and anxiety of his kind relative, " everything seemed altered as he ran along the street. There was the usual entanglement and noise of carts, drays, omnibuses, wagons, and foot passengers; but the misfortune that had fallen on the wooden midshipman made all things strange and new. Houses and shops were different from what they used to be, and bore Mr. Brogley's warrant on their fronts in large characters. The broker seemed to have got hold of the very churches, for their spires soared into the sky with an unwonted air. Even the sky itself was changed, and had an execution in it plainly." Now, if, for argument's sake, we suppose the temporary anxious and fretful state of mind of Walter to have become permanent, then, not improbably, would his intellectual existence have been yet more and more evidently entangled in his over sensitive affections, until at length "delusions" would have manifested themselves-delusions harmonising with the primary and persistent and outraged moral feelings or emotions.

Many patients said to be suffering from melancholia labour, in point of fact, under mania; but, in these cases, the most prominent symptom is grief. The mental alienation is marked to the superficial observer by a dominant and strongly marked symptom of disease; and so it happens, that a cerebral affection, involving perhaps the whole moral nature of a patient, is set down as restrictod to a single faculty or emotion. "Melancholia", so called, is not un- 
commonly only one of the indications of the "moral inanity" of the late Dr. Prichand; and, in such cases, it is common for the patient, in his attempt seemingly to excuse the obstinacy of his feelings, and to explain their absorbing and depressing effects on both his body and mind, to associate, or endearour to associate, his sufferings with some sufficient cause, and thus realise the phantom which pursues and harasses him. Certain it is, that the intellectual life of him so afflicted is wore or less impressed with the character of the most active of his abnormal feelings; and hence does it follow, as in "moral insanity" generally, or, what is the same thing, in instances of a perverted or disordered state of the active feelings, that the reason becomes, to borrow the expression of Lord Erskine, distracted, and frightened from her propriety.

Monomania, regarded as one of the recognised forms of mental alienation, has always proved a bone of contention among both psychologists and legislators. Monomania, literally speaking, is a very rare disorder. Many patients, said to be the subject of monomania, labour under anything but a partial insanity; and, instead of manifesting a disorder restricted to merely one or two subjects, are found, on careful investigation, to present the ordinary signs or indications of mania. Many years agc, i. e., in 1843, there was a great deal said and written about a certain "monomaniac" who had strolled into the precincts of Buckingham Palace. The public mind at this time was much excited on the subject of monomania; the violent death of Mr. Drummond, Sir R. Peel's private secretary, at the hands of Daniel $M$ 'Naughten (a lunatic), had gone far to develope this state of things. There were not a few who advocated, in the columns of the daily papers at that time, the summary execution of all "monomaniacs", and the shelving of all those "mad doctors" who did not acquiesce in so revengeful a proceeding. Well, the poor fellow who had unwittingly intruded himself within the palace walls, was, after the delay of a few days, sent to the Hanwell Asylum. I lost no time in visiting him; but I had to look elsewhere for the unhappy "monomaniac", as the Times paper designated him. The man alluded so was suffering from an attack, not of partial, but general insanity-from, in point of fact, mania. Among the various symptoms of cerebral derangement which his case presented, there was noticed some delusive fancy or the other; this constituted a leading feature, a mere prominent symptom of the alienation which possessed him; and it was therefore seized on and tortured into an importance it could never deserve. As I have already said, whenever a delusion, so called, fixes on the disordered mind, it must be looked on as nothing more or less than a symptom of disease, as a mere effect of a pre-existing cause. That an insane man may be possessed of one delusive idea, is most true; but the brain may be, and is very frequently, otherwise disordered and weakened, though the characteristic delusion is the most striking phenomenon. Writing on monomania, the late Dr. Prichard has these words.

"Nothing, indeed, can be more remote from the truth than the opinion that madmen of this description have their whole disorder centred in and restricted to one delusive idea. The false impression which occasions the disorder to be termed monomania is generally a particular symptom which supervenes on a previously existing affection of that kind, which I have already described as constituting in itself a particular form of insanity, and consisting in a total perversion of the moral character, feelings, affections, and habits of the individual who is the subject of it. One illusive notion, or set of notions, is to be traced in his mind; which, for the most part, occupies his attention, to the exclusion of almost all other subjects, and is ever uppermost in his thoughts; but a careful inquiry will generally show that his whole mind is diseased. There are, indeed, cases on record which answer to the psychological definition of monomania. It is said that persons have continued to exercise their profession, and to conduct themselves with propriety in the relations of life, who have yet been known to labour under one illusion. But if these examples are faithfully recorded, they must be reganded as extremely rare phenomena. The real history of monomanis is very different. It is well known to those who are conversant with the insane, that in persons who are considered as labouring under monomania, the mind is otherwise disordered and weakened; though the characteristic illusion is the most striking phenomenon. The social affections are either obliterated or perverted; some ruling pac sion seems to have entire possession of the mind, and the hallucination is in harmony with it; and seems to have had its origin in the intense excitement of the predominant feeling. This is always a selfish desire or apprehension; and the illusory ideas relate to the personal state and circumstances of the individual. . . They relate sometimes to his fortune, rank, personal identity; at others, to his health of body, and his sensations. In the former class of cases, the patient feels himself unhappy, fancies himself in debt, ruined, betrayed; or, being disposed to an opposite state of feelings, possessed of great wealth and affluence, and superior to all mankind. The difference of these impressions seems to depend on the different state of spirites the persons affected by the former kind of impressions are those whose minds are predisposed to gloom and foreboding. of ill ; the latter kind affect the sanguine and excitable."

Moral Insanily is a subject on which much has been written and said. It is a form of mental disorder not eren yet sufficiently recognised by professional men; and as to the lawyers, they socm, with a few exceptions, to reject all medical experience and discovery. Dr. Prichand wrote much and earnestly on Moral Insanity; it is described by him as " a form of mental derangement which consists in a morbid perversion of the feelings, affections, and active powers, without any illusion or erroneous state impressed on the understanding; it sometimes coexists with an unimpaired state of the intellectual faculties." Now, gentlemen, this is precisely the fact in the majority of cases of mania so called, and particularly so during the "incubation of insanity". Mania, indeed, is commonly nothing more or less than an acute "moral insanity", correctly considered, in which the too quick succession of the morbid feelings and propensities is disproportionate in a general way to the power of utterance. This state of things it is which renders the speech incoherent; the tongue then is not lively enough to give expression to the rapid emotion: which prey on the patient. The several cases given by $D r$. Prichard to illustrate what he conceived to be moral insanity, were instances of every day mania, in which the intellectual faculties had escaped the ravages of the disease affecting the emotional qualities of the mind. I am disposed to think that, under the circumstances, it would be well to limit the application of the term "moral insanity" to those cases wherein a congenital and well marked predis position to the indulgence of the lower feelings and animal desires is manifested; to such cases as Dr. Mayo has applied the term "brutality". I would refer you to Dr. Mayo's Pathology of the Human Mind for valuable information on this head, whilst I content myself by remarking merely that the author treats of "brutality" as a moral idioes, and as holding the same relation "to the heart" (Dr. Mayo prefers to express himself in figurative language), that the various degrees of imbecility do to the brain. "It (i.e., brutality) implies", writes Dr. Mayo, "a destitution of principle, while insanity implies a perversion of tendencie and a want of self-control. In the latter case, the patient cannot hear the roice of conscience; in the former case, he has no conscience to hear." The shocking scenes which every now and then occur at our police courts furnish ws with examples of individuals who would seem to have come. into the world but "to bite mankind and play the devil", as Shakespeare has it. Such patients-for such they must, be called-who belong to the lower walks of life, paes their: lives either in the private indulgence of their criminal en-. thusiasm, or in expiating the same within the walls of $a$. penitentiary or common jail, to sey the. least of it; whilet, those born under other circumstances, and perhaps in affuence, are-after long years of anxious solieitude on the pardo 
c. the matives and friends, who aro at a loss to what cins to attribute the "moral idioey", the "brutality" manifeoted in one of their own blood, and under circumtances 80 foreign to both the derelopment and practice of immoral habits and criminal pursuits-at length, and as a very general rule, sent to a private asylum. I am well scquainted with two persons holding the rank of ladies, who mas be said to live only in such an atmosphere of deformity and vice. There is much reason to believe that, if all controlling power were remored from these partiesi.e., if they were left to themselves, to their own individual hikes and dislikes-they would each of them be found to realise the most painful infringement of the moral laws; they would lie, steal, drink, quarrel, for the mere love of rach animal excitants, and not because there was either a reeming motive for the concealment of truth, or any real want experienced, or bodily or mental exhaustion or ennu to reliere, or personal offence to be arenged or retaliated. All such are indeed, even from their birth, a law unto themelves, but a very bad law, one compatible only with the gratification of the lower feelings, the vicious propensities.

According to Dr. Mayo, the notorious Lord Wharton laboured under this " moral idiocy". Swift says of him: "I hare had the honour of much conversation with his lordahip, and am thoroughly convinced how indifferent he is to applause, and how insensible to reproach; which is not a humour put on to serve a turn, or meet a countenance, nor arising from any consciousness of innocence, or any grandeur of mind, but the mere unaffected bent of his nature. He is without the sense of shame or glory, as some men are without the sense of smelling; and therefore a good name to him is no more than a precious ointment would be to these." The unhappy Lord Ferrers affords another erample of this form of congenital alienation, i.e., "moral idioey"; but "the laws of his country did not reach him as a subject for confinement" (Mayo); and he was therefore hanged.

The annered case is reported by the elder Pinel, as an illustration of "manie sans délire", or of the " moral insanity" of Prichard. "An only son of a weak and indulgent mother was encouraged in the gratification of every passion and caprice of which an untutored and violent temper was susceptible. The impetuosity of his temper increased with his years; every instance of opposition or resistance roused him to acts of fury. He assaulted his adversary with the audacity of a sarage, sought to rule by force, and was constantly embroiled in disputes and quarrels. If a dog, a horse, or any other animal, offended him, he instantly put it to death. If ever he went to a fete or any public meeting, he was sure to excite tumults, and generally left the scene with a bloody nose. This wayward youth, meanwhile, when unmoved by passion, possessed a perfectly sound judgment. When he came of age, he succeeded to the possession of an extensive domain. He proved himself perfectly competent to the management of his estate, as well as to the discharge of his relative duties; and he even distinguished himself by acts of benerolence. Wounds, lawsuits, and pecuniary compensations, were, however, still the consequence of his mhappy propensity to quarrel. But an act of notoriety put an end to his career of violence. Enraged at a woman who had used offensive language to him, he threw her into a well; prosecution took place; and, on the evidence of several witnesses to his furious deportment, he was condemned to perpetual imprisonment in the Bicêtre."

I quite agree with Dr. Mayo in thinking that the foregoing is a very fair example of moral idiocy - of, in point of fact, moral insanity. It is true that many boys show a certain vilfulness in their conduct, a viciousness in their propensities; but they are, as a very general rule, sooner or later brought into other habits, and successfully encouraged to the exercise of their better feelings. But the exception now and then, though very seldom, presents itself. Let us hope that a parallel incorrigibleness to that just detailed is but rarely witnessed. The fact, howerer, is an important one in a psychical view, and must not therefore be lost ight of. Dr. Mayo very properly remarks, that, " in regard to the principles on which this morbid condition may be treated, the law greedily takes advantage of its coexistence with ordinary insanity, whenever this occurs (and it readily does occur), to control the unsound habit of mind; but it has not hitherto been able to grasp it in its own form: although, in truth, the state which we term 'brutality' spreads as wide devastation as insanity would, if insanity were left uncontrolled; and is, according to the above view, equally a disease of mind."

The following instances of this "bent", when placed in jurtaposition, and considered relatively to each other, afford a striking proof of the value of Dr. Mayo's views on this very important medico-legal question.

"Mr. A. was born in a respectable station, and is in possession of a good fortune-of as much, at least, as he has allowed to remain out of a good fortune. He has a wife and children, and as many friends, or rather associates, as his convivial qualities retain for him in spite of the hardness of his character. He has always been profusely extravagant; for his passions and appetites have compelled him to squander money, which he would probably have hoarded, if his selfishness had taken that turn. His temper is at once stern and violent; and all who know him expect that the disposition of his will must prove him, to the last moment of his life, utterly unjust. If he had sufficient courage, he would rob and murder; for his cupidity is under no moral check; but he is naturally very timid, and owes to this circumstance his freedom from such acts as the law construes into crimes. Such is Mr. A.; and such also, or as nearly such as the distinctive points which separate all individuals will allow, is Mr. G., his near neighbour. But there happens to exist a peculiarity in Mr. G. which materially alters the course of his life, and its results upon others. Mr. $G$. was observed to talk very much to himself; this excited attention, and, on further inquiry, it was discovered that he was habitually under the influence of false perceptions; and that he considered himself solicited by certain voices, audible only to himself, to perform those actions, which indeed flowed naturally enough from his own evil dispositions. Mr. G. was accordingly recognised as a lunatic, and placed under restraint. Thus the family of Mr. G. is secured against the results of his moral [or rather immoral] character; and his fortune will descend according to the principles of law; thus dealing out a justice to others and a protection to him which would have been refused but for his hallucination"

The nature and proximate cause of insanity is the next subject for our consideration; and a very important and interesting subject it is. The contents of the first lecture will have prepared you, to say the least of it, for the seat of the proximate cause of insanity, if not for its nature. You will remember, then, that the brain has been considered as that portion of our organism by means of which the adaptation of man to the external world is in an especial manner made manifest. The external senses, ever on the alert, as good and trustworthy sentinels, supply to the brain an unceasing stream of knowledge of all the facts and circumstances which may surround us; and by means of these, and their relationship to the brain, the central organ, the affections of man are called into being, and his sympathies are awakened; the emotions also are similarly excited to action, and the deep passions of our complicate nature aroused. Upon the integrity of the external senses man relies also for the stimuli necessary to the development and perfectibility of his intellectual powers. The cerebral mass itself is in every way adapted, by its peculiar organism, to the performance of these wondrous offices in the animal economy, composed as it is of various and dissimilar parts, each one ministering in its especial manner to the mental entirety of the individual. It must be remembered that the essential material of a nervous system-that, in fact, by which it is distinguished from every other, and upon which the peculiar attributes and powers of the system depeid-is not uniformly alike; it is not homogeneous; it is not ererywhere the same. Its physical properties are different in different situations: in one, its colour is grej, 
and its terture is soft and pulpy; in another, it is white and distinctly fibrous; and these two are not found indiscriminately mingled, but the grey or pulpy matter is always met with in a ganglion, and the fibrous alone enters into the composition of a nerve, while the commissures are occasion ally compounded of the two. From these and other circumstances, it is fairly concluded that the peculiar power of the nervous system resides in the grey or cineritious portion, and that the office of the medullary is simply that of a conductor. This conducting power may be described as of a threefold kind.

1. As a conductor of the stimulus which arouses the cineritious neurine into action-the nerves of sensation.

2. As a conductor of the will, which originates in the cineritious or pulpy neurine (nerves of motion or volition).

3. As an agent for the purpose of combining the various impressions conveyed to the cineritious neurine in the ganglion, which may then be viewed as a centre of power (commissure).

Viewing the brain, then, as the instrument or bond of union between man and all external objects, and its grey matter as the origin or source of the various emotions, sentiments, and propensities, and not less the seat of both the perceptive and reflective, i.e., the intellectual powers; viewing, I say, the convoluted surface as the seat and source of power of and to the various primitive mental faculties, by whatsoever name recognised, and not less the measure of their activity and endurance, and considering the white or medullary structure as the conductor to and from it of the various sensations and forms of volition which belong to our nature, and its union with, or dependence on, the external senses for the stimulus to which it (the grey matter) may be said to owe much of its integrity, we are directly led to appreciate not only the structures more directly involved in cases of insanity generally, that is, of deranged emotions, sentiments and propensities, but the mutual dependence of the grey and white substances, and their co-operation as a condition of health, and contrariwise. If the production of the nervous power in a state of health is due, as it undoubtedly is, to certain and oft recurring physical changes taking place in the cerebral organism, and this the result of nothing more nor less than the difference between the organic and chemical properties which distinguish the grey and medullary substances respectively, it must follow that any cause calculated to interfere with such certain and physical changes, whether it operate by increasing or by diminishing their frequency, or by altering their order of succession, must, if it exceed certain limits, lead to the secretion of a "nervous power" of so altered a quality or quantity as to induce disease, i.e., insanity. Or, to go further, if the organic or chemical properties which distinguish either the grey or the medullary substance become altered in any way, -if the "fatty matter", or " osmazome", or "albumen", or "water", lose their legitimate or normal form of combination or relative proportion, in either or both of these structures, and so assume another character, and present en nzasse a dissimilar colour or consistence, and so on, it must follow that the physical changes just referred to must be materially and injuriously affected; and if these morbid alterations occur to the grey matter (which is, I think, more commonly the case, this being the source of power to the other parts of the brain), then will one or more of the emotional feelings or propensities, or of the intellectual powers, give evidence of deranged action, according to the location and extent of the convoluted surface brought under the influence of diseased action. The application of the facts and principles above insisted on to the every day history of individual cases of insanity is alone necessary to verify the origin and seat of this dreadful malady.

The word " neuralgia", as you are aware, implies a morbid sensibility of one portion of nerve-matter, i.e., of a sentient nerve or nerves, and this morbid sensibility is indicated by pain. Now the same state of things may occur to the motor nerve-fibre; but in this case, there will be no pain. Your patient will then labour under chorea, or some dis - ordered condition of the motor power. It follows, then, that apecific and disordered state of the nervous atruc tures may be indicated by symptoms at once evident and dissimilar, according to whichever portion of the nervous organism is injured or affected. Now, of the presence of neuralgia, the patient is unhappily but too conscious; but, on the occurrence of morbid sensibility to the sensorium, he is without pain, and he may, therefore, be said to be unconiscious of the fact; he does not, then, feel the morbid sensibility as such. The brain is over susceptible to all ordinary impressions from without, and, therefore, it is in nary impressions from without, and, therefor, it sensibility; and this is altogether independent of mere animal sensation.

Dr. Billing, in his Principles of Medicine, demonstrates that " the consequence of the brain or spinal cord becoming in a state of morbid sensibility is, that their healthy actions are deranged; that is to say, in health, the brain communicates to the muscles of voluntary motion the dictates of the will only; but if the origin of the voluntary nerves of a part in the brain be in a state of morbid sensibility, or if a perted condition of the part of spinalis, through which the nerves pass, exists, that part may be thrown into action independently of the will, or even against its dictates." It will appear, then, that among the insane, the "nervous power", of which mention has been made, is, as a general rule, i.e., under circumstances of excitement, as in mania (acute and chronic) converted into "irritation" or "morbid sensibility;" and that this fact is well illustrated by the origin and progress of almost. any case of mental derangement. Long continued mental exertion, protracted anxiety, or excessive action of any one or more of the cerebral faculties, lead, ere long, to a morbid sensibility of a portion or portions of the cineritious neurine; this, the source of power, intellectual and emotional, if overtasked, loses, like, any ordinary muscle, the capacity to respond duly to the too frequent and long continued calls made on it ; and it assumes, therefore, a condition of irritation (excitement without power) which, if allowed to proceed unchecked, or if not relieved, realises all the external indications of mental derangement. The brain (grey neurine), like the spinal cord, or like any other portion of animal matter, is subject to precisely similar organic laws; and if we would avoid the consequences of their infringement, man must learn to discriminate between their use and abuse, avoiding the latter. The following are interesting and instructive illustrations of the abuse of the said "organic laws", as shewn in the effects on the human organism of the various emotions and passions when urged to excess, or intemperately protracted. That they tend to confirm the truth of the foregoing statements, will he directly apparent to you; and what is more, they afford good ground for believing that Dr. Billing does not exaggerate the dangerous consequences of "long continued mental exertion", or "excessive action of any one or more of the cerebral faculties", when he insists that these, or what is the same thing " mental excitement", such as anger, grief, fear, etc., which are analogous to the direct irritation of the brain or spinal cord by a depressed fracture or spicula of bone, will produce the state of morbid sensibility of the nervous centres, indicated by involuntary, or almost involuntary muscular actions, even by epileptic fits. In vol.iv. of Good's Study of Medicine, we learn that Cardan, an Italian physician, records the case of an artizan of Milan, who, having had the good luck to find an instrument that formerly belonged to Archimedes, went mad with the fit of transport into which he was hereby thrown; and Plutarch, in his Life of Artaxerxes, has a like story of a soldier who, having had the high honour of wounding Cyrus in battle, became so overjoyed, that he lost his wits from that moment. "Occasionally", writes Good, "the exhaustion of sensorial power hereby produced is so sudden and total, that the whole nervous system seems instantaneously to become discharged of its contents, like the Leyden phial loaded with electricity, when touched with a brass rod, and death takes place at the moment. There are various instances on record in which 
10 to fec has followed upon the injudicious preduction of - iparion to soulprit juet on tho point of his boing turned the sillow. Valerius Meximus relates two enocdotes of matroese, who, in like manner, died of joy on seeing their eans ruturn afe from the bettle at the Lake Thrasis; the ene died while embracing her son, the other had been misifformed, and was at that moment lamenting his death." Dr. Good adds: "Many a crown won by good fortune, and Which might have been preserved by moderation, has been lost by the delirium of pride and vain glory, of which the history of Denetrius of Macedonia furnishes us with one of the most memorable examples. He, in his disgraceful fill, was obliged to abandon, among the other idols of his heart, the unfinished robe which was to have hung over his choulders, containing a magnificent embroidery of the sun, the moon, and all the stars of heaven, designed to have represented him as the sovereign lord of the whole.

"But if such be a frequent effect of the stirring passions of a pleasurable kind, it is not difficult to conceive that thowe eccompanied with pain, as the passion of anger, and all its compounds, suspicion, revenge, and especially jealousy, must make a much wider inroad upon the domain of - well-ordered mind, and introduce confusion and derangement. Nor is the effect confined to the brain; for a stimulus, thus violent, affects the entire system, and, as we have chready observed, has a peculiar sympathetic influence on the liver, producing, in many instances, a very diseased secretion of the bile, and altering it, in a very short period, not only in its quality, but in its quantity. At the same time, every vessel is exhausted of its irritability, and the whole strength is so prostrated, as occasionally to lead on to obstinate faintings, convulsions, and death.

"The expressions and gestures are always violent and offensive, and are similar to those of maniacal rage; the oyes are red and inflamed; the countenance is flushed, swollen, and distorted; and the person is ungovernable.

"Such was the case, in 1392, with Charles VI of France; who being violently incensed against the Duke of Bretagne, and burning with a spirit of malice and revenge, could neither eat, drink, nor sleep for many days together, and at length became furiously mad as he was riding on horseback, and drawing his sword, struck promiscuously everyone who approached him. The disease fixed on his intellect, and accompanied him to his death."

The last days of our own Elizabeth furnish an additional illustration of the ill effects of the application to the " grey matter" of a stimulus too intense and long continued, or, what is the same thing, incompatible with the healthy uses of the cerebral mass. The life of this once popular princess was plainly sacrificed to her female vanity.* Enraged beyond endurance at what she conceived the slights of her farourite, the famous Earl of Essex, her haughty and imperious nature leaped all bounds of prudence and foresight. Itung by remorse and grief for having, under the operation of strong and vehement passion, ordered the execution of that nobleman, her mind knew no repose; sleep fled from her couch, $i$. e., speaking figuratively, (she died on the floor of her apartment, where she had lain for several preceding days,) and she sank into a deep melancholy. The bodily exhaustion which thus resulted was greatly aggravated by her refusal of all food and medicine, and in a few weeks she expired under the accumulated pressure of an "acute melancholia", the offspring only of her own abuse or infringement of the organic laws, to which, I need not add, we all owe obedience and enjoyment.

One more anecdote $I$ cannot resist; it is a very affecting one; you will find it in the late Dr. Uwins's Treatise on Disorders of the Brain. "A lady, on the point of marriage, whose intended husband usually travelled by the stage coach to visit her, went one day to meet him, and found instead of him an old friend who had come to announce to her the sad tidings of his sudden death. She uttered a ecream, and piteously exclaimed ' He is dead!' but then all consciousness of the affliction that had befallen her ceased.

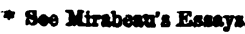

From that fatal moment", says the suthor, "has this unfortunate fomale daily, for fifty years, in all seasons, tra ressed the distance of a fow miles to the spot where she expected her future husband to alight from the coach; and every day she utters, in a plaintive tone, ' $\mathrm{He}$ is not come yet! I will return to-morrow."

That insanity is primarily a disorder of the nerrous rather than of the vascular system, and is, moreover, the direct sequence or accompaniment of a morbid sensibility of the cineritious neurine, $i . e$, the convoluted surface of the brain, is further proved by its occasional temporary and ephemeral character. I knew a young gentleman, of acute foeling and keen sensibilities, and, like the generality of those of a well marked sanguine temperament, much addicted to the opposite sex, though by no means sensual. His heart-strings knew little repose; at length they experienced a sudden and severe concussion, one for which he was ill prepared. Within the space of two hours he realised a complete attack of acute mania. This circumstance occurred many years since, and from that time to the present he has exhibited no kind of approach to mania, or to any other species of mental derangement. Some years ago, when in general practice, I attended a lady in her accouchement; she was delivered of twin children; all went on most satisfactorily, until the afternoon of the fourth day, when I was sent for in the greatest haste. I found her literally raving mad; in a high state of delirium, wild, and furious with rage. In something less than half an hour, the paroxysm had subsided, and what is more, it has never returned, though since this she has had a tolerably large family. It is said that the celebrated Dr. Fothergill, otherwise a very sober minded man, was all at once seized with the mania of walking naked through the streets of Edinburgh, and preaching repentance. A German writer, Feuchtersleben, in his Medical Psychology, translated by the late Mr. H. Evans Lloyd, and revised and edited by Dr. B. G. Babington, reports the case of a young man, in perfect health, who awoke suddenly one night in a fit of raving madness, ill treated his wife, attempted to leap out of the window, and struck at whatever came in his way. An emetic put an end to this scene in one hour; after which he continued in a perfect state of health, never having had a recurrence of the attack. The never ending suicidal deaths, as reported by the newspaper press, suggest the frequent occurrence of this isolated or ephemeral form of alienation. Unhappily, in such instances, we know only the sad and fatal climax of the disorder; but if, for example, this had been stayed by some accident in the cases which so lately occurred at Portsmouth (those of two gentlemen who retired to bed at their hotels, each in excellent health, but each of whom threw himself from his window before morning dawned, and so was killed), it may have turned out that these were parallel cases to that of Dr. Fothergill, and especially to that of the young man just mentioned.

The peculiar mode in which insane affections now and then terminate, affords much additional reason for the foregoing opinions. We have seen that the accession of maniacal disorders may be not only sudden, but that the same may be either "isolated", i.e., ephemeral, or persistent; now the latter, viz., the persistent disease, is sometimes, though rarely, terminated by recovery, temporary or otherwise, in the most extraordinary way, and under the most peculiar circumstances. The following case is recorded by the late Dr. Gooch: "A lady, who had been suffering for some time from puerperal mania, was suddenly brought into the presence of her husband, whom she believed to be dead; the effects were magical. She has since then continued perfectly well, and has had another child, without the slightest threatening of her former malady."

The following observations are from a small book of my own devoted to the consideration of the subject of this lecture. "During my recent connexion with the New County Asylum at Colney Hatch, a poor woman, an inmate of the establishment, admitted when pregnant, was seized with labour pains. These continued, and in the most natural manner, passed from bad to worse; in pro- 
portion to their soverity did the mind recover its former lost tone. On delivery taking place, and for two subsequent days, my patient was not less sane than myself: however, her cure was a very temporary one; she quickly relapsed into her former wild, fanciful, and incoherent manner and speech."

It is well known that insane persons occasionally, on being attacked with acute disease, as well as on the receipt of accidental injury, become perfectly sane; I have met with many such cases. An inmate of Hanwell (1843), the subject of chronic mania, suffered from a severe form of pleuropneumonia. Directly on the accession of the new disease, the brain perfectly recovered its tone; the disordered mind was cured; but when, after a few days, the morbid affection of the respiratory organs was relieved, when its symptoms had yielded to appropriate treatment, then the cerebral derangement returned. A young woman (insane many years), who had long been suffering from phthisis, became, about eight hours before her decease, so gane as to talk not only most rationally, but in the most affecting manner of her illness and near dissolution. This case produced a strong impression on the infirmary attendants, from the strong contrast furnished in the state of mind of the patient just before her death, and on all former occasions, as a more maniacal person, literally speaking, could hardly be conceived. An insane patient under my care had a large carbuncle over the inferior angle of the scapula; the local symptoms were very urgent; she suffered intense pain in the part, in spite of the free incisions made through its substance. From its occurrence to the separation of the gangrenous cellular tissue, or until the wound began to suppurate kindly, this poor woman gave no evidence of deranged mind; but no second carbuncle made its appearance, and she relapsed into her previous madness. A maniac accidentally fell down some stone steps, and thereby received a severe contusion of the forearm; this was followed by "low cellulitis". (See S. F. Statham's Sketch of Low Inflammation.) On one occasion of my visiting her, and on hearing me give some directions to the infirmary attendants, preparatory to my making incisions into the part so affected, she, to my great astonishment, addressed me after the most sane and approved manner concerning the mishap which had befallen her, and the chances of her recovery therefrom. She continued in the possession of her mental faculties for about eight or ten hours, when, after some general signs of nervous excitement, she became more or less delirious. An irregular kind of epileptic attack succeeded the exaltation of the cerebral functions; and after a few hours she died.

Sir Astley Cooper, in his work On Dislocations and Fractures, records the case of a gentleman afflicted with mania, who, being left alone, seized the opportunity and jumped out of the window of his apartment, on the third story, into the street; and alighting on one of his feet, sustained a compound fracture of the ankle-joint. From the period of the occurrence of the accident, the indications of insanity left him. He quite recovered. This gentleman sustained only a temporary inconvenience from the injury.

During my official connexion with the Hanwell asylum, one of the epileptic patients, an imbecile girl, who had so many as four or five convulsive attacks each day, when out walking fell down a steep bark, and, alighting on some heavy stone-work, received a lateral dislocation of the foot, with fracture of the external malleolus. Although she was under surgical treatment for a period of nearly two months, she was, during the whole of this time, without a single epileptic seizure; but no sooner was the use of the extremity restored to her, than the attacks returned with their former frequency and severity. This girl, I may add, had been the subject of epilepsy for ten or twelve years.

Mania and epilepsy are equally the external and physical manifestations of a "morbid sensibility" of portions of neroe-matter. The alienation of the one, like the convulsion of the other, but too plainly indicate a want of balanoe between the nervous and vascular forces, the former being in excess. The specific and remedial effects of the loeal injury in either case on the brain or spinal cond an be, perhaps, but a matter of conjecture at the present time. Dr. Billing, horrever, accounts for the occurrence of phenomens like to those above detailed, by the fact of a cartain mena like to those above detailed, brain taking place, and thereby altering the active character of the complaint.

It is impossible not to be struck with the analogy prosented between the foregoing facts and the every day history of the neuroses generally. Mania, neuralgia, hysteria, chorea, tetanus, asthms, and angina pectoris, may be alike sudden and of temporary duration. Each and all of them named may be either remittent or paroxysmal ; and, what is mare, each and all of them may, and do sometimes, and all at once, disappear, and that eren after long years of ondurance, and without any of the usual signs of amendment preceding the restoration of the party afflicted.

To carry out the parallel with which I commenced the discussion of this part of my subject, I would add, that it is quite necessary that pathologists should be prepared at this time with more correct views of insanity than those too generally entertained. All know well the relation of neuralgia to the sensory nerve-fibre; of chorea or tetanus to the motor track, or its dependencies; of asthma to the pulmonary nerves; of angina pectoris to the cardiac; all practitioners are prepared, I take it, to explain the dopendence of either one or the other of the diseases here named, of neuralgia, chorea, etc., on "a morbid sensibility" of specific portions of nervous structure, grey or white; but all do not so well know, it would seem, that the only difforence between maniacal affections and those I have just named, is in the seat and not in the nature of the disonder. The parts first or directly affected in those several morbid conditions enumerated, exercise, as a general rule, certain functions in the animal economy; i.e., they contribute their respective aids to the animal functions which, combined, constitute the life of the individual; but exceptions now and then occur, and the same parts then exercise an abnormal influence-contribute, not aids, but obstructions to the animal functions in a state of health; or, in other words, what was use becomes abuse. Disease is set up in the nervous system; and the nature of this will depend on that portion of the nervous organism affected. If it be in the grey matter of the brain, insanity in some shape or the other will show itself; if it be the grey matter of the cord, sensation will be deranged; if it be in the medullary or white fibrous matter of the brain or cord, either volition or motion will be impaired; and so on: and hence the occurrence of not only mania, but of neuralgia and anæsthesia, of tetenus, chorea, paralysis; and what is a very material point, each and all of which-not forgetting asthma and angina pectoris-(to carry through the simile)-are commonly, in chronic cases, complicated with an asthenic inflammation of the vascular tissue of particular parts, the usual signs of which are not only discoverable after death, but are indicated, more or less plainly, during life.

By whatever name we may recognise the several disordered conditions of the nervous system-i.e., the neuroses so called-whether mania, neuralgia, chorea, asthma, angina pectoris, etc., we find, as a very general rule, that the subjects of them are of a delicate and enfeebled constitution, and endowed with a morbid susceptibility. The frequency of the occurrence of insanity among the poorer classes is proverbial. The greater number of its victims, in all classes of society, exhibit the more common signs of an acquired constitutional debility. In fact, all those of lax fibre and of weak and delicate health; all those whose nervous organism is incompetent to a prolonged exertion or a sustained volition directed to the acquirement of the means of support, are especially prone to mental alienation, in some one or other of its Protean shapes. The poorer classes - the unhappy victims of a depraved and exhausting physical regime-extended over successive generations, inherit all the seeds of impaired mind, in virtue of an imperfectly matured nervous or cerebral organism; and these, therefore, are very liable to insanity. But each and all of these, to whatever class or station of life he or they. may 


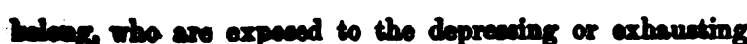
nneses on the brin and narrous astem of long watchin protrocted labour, or insufinieient or unwholecome food, an: Exally be expected to cecape with impunity. That inmits is conentially a disease of debility, is made evident, not onls by it occurring very much more commonly than ctherwive to those who have either inherited a weatly and delicate constitution, or whose various excesses or extravaancies of life, or misfortunes, hare induced such a state of things; but by its attacking persons who may happen to be expoed to any accidental or temporary cause of exhaustion, weh as homorrhage, night watching, long fasting, the puerperal state, long continued and violent pain, the depreasing passions, and so on. Now, in all such patients, it must be directly conceded that the absence of all signs of a phlogintic diathesis precludes the bare idea of inflammatory action of either the brain or its membranes. The symptoms which characterise the mental : disorder in each are not those belonging to an increased vascularity ; the heart's action is rapid, but foeble; the:temperature of the skin is not generally increased; nor is the countenance flushed. The great excitement and well marked restlessness; the unceasing mobility; the rapid succession of ideas, and consequent incoherence of speech; the wildness of manner, and automaton-like movements, which mark an attack of acute manis, -are then the direct effects of a morbid sensibility of the cineritious neurine or grey matter of the brain. What was " use" or power has become "abuse", or action without poroer; and this is the consequence of the application of a stimulus too intense or long continued, or disproportionate, in some way, to the healthy physical capacities of that portion of the cerebral structure named.

The proximate cause of insanity is a morbid sensibility of the convoluted grey substance of the brain.

Impressed with the importance of the subject which now engages our attention, $I$ have been at some considerable pains to collect at one view, in the tabular forms appended to this lecture, the practical results of my own investigations into the essential cause of insanity, carried on in the dead-house of the Hanwell Asylum. These extended over a period of about four years, and were commenced and carried through without any preconceived views or theory in relation to this department of our profession; and the fects.here put before you are therefore the more likely to be fairly and honestly set forth. It cannot be doubted that the most conscientious of us are hardly proof against some amount of prejudice and inconclusive reasoning; so surely do the external senses in man become, under certain circumstances, the mere tools of the other faculties, persuading if not absolutely leading them into error, from which escape is sometimes hardly possible.

TabLE I.-Of 100 Insane Persons examined, there had been affected with-

Mania $. \ldots \ldots \ldots \ldots \ldots \ldots \ldots \ldots \ldots \ldots \ldots \ldots \ldots, 19$

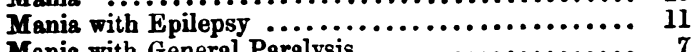

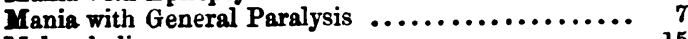

Melancholia ............................... 15

Dementia .............................. 19

Dementia with Epilepsy................... 7

Dementia with General Paralysis............... 3

Dementia with Epilepsy and General Paralysis...... 2

Total $\ldots \ldots \ldots \ldots \ldots \ldots \ldots, 83$

Form of disorder not stated .... 17

Grand Total ............... 100

In Table No. $I$ is shown the numerical proportions of manis, dementia, and melancholia; and the complications of the two former with epilepsy and general paralysis, to the whole number of cases examined, viz., 100 . I have preferred to confine my attention to a single hundred cases, hoping, by so doing, to give a more specific and practical character to the mode of inquiry adopted; and believing the same to be in all respects sufficient for the purposes inteaded. It may be fairly preaumed that an analysis of a so- cond or of even sthind hundred would but add to the trouble of arrangement, without in any approciable way adding to the value of the conclusions to be drawn therefrom.

Tabne II.-Of 100 Bodies of Insane Persons examined, the (HEAD)

Calvarium was affected in $\ldots \ldots \ldots \ldots \ldots \ldots \ldots \ldots \ldots .24$

Durs Mater ............................... 15

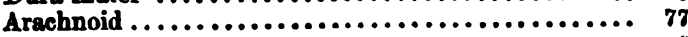

Pis Mater .................................. 0

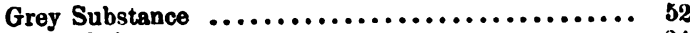

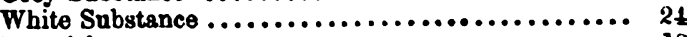

Ventricles ............................... 18

(THORAX)

Heart and Pericardium

Lungs and Pleure ........................ 44

(ABDOMEN)

Stomach, Bowels, and Peritoneum ............... 20

Liver and Spleen ..........................., 18

No Morbid Appearance was observed in ............ 8

In Table No. II are demonstrated the relative proportions, in the 100 cases examined, in which the various parts of the cerebral mass and its coverings, including the calvarium, were severally affected, i.e., presented indications of disease, or alterations from the normal standard.

Tabie III.-In 100 Bodies of Insane Persons examined, the CALTARIUX WAS FOUND AFFECTED IN 24.

In 15 there was unusual thickness generally.

In 1 there was unusual thickness purtially.

In 2 there was unusual thinness generally.

In 3 there was unusual thinness partially.

In 1 there was partial absorption of the Inner Table.

In 1 bony matter partially filled the Middle Fossa.

In 1 a prominent ridge rose from the Petrous Bone. DURA MATER IN 15.

In 12 it adhered to the Calvarium.

In 3 it adhered to the Arachnoid.

ARACHNOID IN 7 \%.

16 Serous. Effusions on its surface in $21\left\{\begin{array}{l}10 \text { Sero-Sanguineous. } \\ 3 \text { of Blood. }\end{array}\right.$

More or less opaque in 34 .

Effusions beneath it in $50\left\{\begin{aligned} & 48 \text { Serous. } \\ & 5 \text { Sero-Sanguineous. } \\ & 2 \text { of Blood. } \\ & 1 \text { of Lymph. }\end{aligned}\right.$

PIA Mater in 6 .

In 4 it adhered firmly to the Brain.

In 2 it adhered firmly to the Arachnoid. GREY SUBSTANCE IN 52.

In 14 it was paler than natural. In but one of these it was also soft.

In 19 it was darker than natural.

In 12 it was softer than natural.

In 8 it was firmer than natural.

WHITE SUBSTANCE IN 24

In 16 it was softened in various degrees.

In 8 it was indurated.

VENTRICLES IN 18.

In 16 they were distended with serum in various degrees. In 1 the roof and floor were adherent.

In 1 small Serous Cysts were attached to the Lining Membrane.

Confining my attention to the head, it is proper I should remark here that the appearances, post mortem, of the several structures enumerated in this table, are those which belong for the most part to either past or the then present inflammatory action; but this fact the Table No. III is well calculated to prove; and for this especial purpose it has been prepared.

To the Table No. IV, I would invite your especial attention: it is intended to demonstrate the entire want of correspondence, heretofore insisted on, between the several disorders known as varieties of insanity and individual poat mortem appearances. In 8 of the 100 cases reported, it is seen, there were no morbid appearances found on exsmination. 
TAsus IV.-Siructures and Organs affected, their Proportion and Relation to Particular Forms of Mental Disease.

\begin{tabular}{|c|c|c|c|c|c|c|c|c|c|c|c|c|c|}
\hline $\begin{array}{l}\text { Yo. of } \\
\text { cases. }\end{array}$ & Form of disorder. & $\begin{array}{l}\text { Calre- } \\
\text { rium. }\end{array}$ & $\begin{array}{c}\text { Dura } \\
\text { Mater. }\end{array}$ & $\begin{array}{l}\text { Arach- } \\
\text { noid. }\end{array}$ & $\begin{array}{c}\text { Pia } \\
\text { Mater. }\end{array}$ & $\begin{array}{l}\text { Grey } \\
\text { sub. } \\
\text { stance. }\end{array}$ & $\begin{array}{l}\text { White } \\
\text { sub- } \\
\text { mtance. }\end{array}$ & $\begin{array}{l}\text { Von. } \\
\text { tricles. }\end{array}$ & Heart. & Lungw. & $\begin{array}{l}\text { sto- } \\
\text { mach, } \\
\text { bowels, } \\
\text { and } \\
\text { perito- } \\
\text { neum. }\end{array}$ & $\begin{array}{l}\text { Iiver } \\
\text { and } \\
\text { spleen. }\end{array}$ & $\begin{array}{l}\text { No } \\
\text { morbis } \\
\text { appear- } \\
\text { ence. }\end{array}$ \\
\hline $\begin{array}{r}19 \\
11 \\
7 \\
15 \\
19 \\
7 \\
3 \\
2 \\
17\end{array}$ & 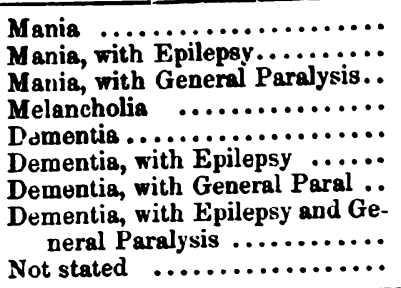 & $\begin{array}{l}4 \\
1 \\
3 \\
1 \\
7 \\
-\end{array}$ & $\begin{array}{r}3 \\
\mathbf{2} \\
\mathbf{1} \\
\mathbf{3} \\
\mathbf{1} \\
\mathbf{1} \\
\mathbf{1} \\
-\mathbf{3}\end{array}$ & $\begin{array}{r}9 \\
10 \\
8 \\
12 \\
18 \\
-3 \\
2 \\
14\end{array}$ & $\begin{array}{l}- \\
-1 \\
- \\
-1 \\
1\end{array}$ & $\begin{array}{r}14 \\
0 \\
3 \\
4 \\
15 \\
1 \\
2 \\
2 \\
5\end{array}$ & $\begin{array}{l}4 \\
2 \\
3 \\
2 \\
6 \\
2 \\
2 \\
-3\end{array}$ & $\begin{array}{l}1 \\
2 \\
2 \\
3 \\
2 \\
2 \\
3 \\
\\
1 \\
2\end{array}$ & $\begin{array}{r}0 \\
6 \\
3 \\
3 \\
2 \\
- \\
-3\end{array}$ & $\begin{array}{r}11 \\
3 \\
2 \\
8 \\
12 \\
3 \\
- \\
5\end{array}$ & $\frac{6}{-}$ & $\begin{array}{l}8 \\
1 \\
-1 \\
-\end{array}$ & $\begin{array}{l}2 \\
1 \\
2 \\
1 \\
-\end{array}$ \\
\hline 100 & All Forms $\quad \ldots \ldots \ldots \ldots \ldots \ldots$ & 24 & 16 & 77 & 6 & 62 & 24 & 18 & 26 & 44 & 20 & 16 & 8 \\
\hline
\end{tabular}

Now, gentlemen, it will directly occur to you, in running your eyes over those tabular forms, that the very common occurrence of morbid action in the membranes of the brain, and particularly in the arachnoid, cannot be without its importance, regarded either as a cause or consequence of disordered mind; nor is it. You are probably aware that Bayle was so struck by the conjunction of meningitis with insanity, that he was led to adopt an original theory of the disease. In his work, entitled $A$ New Doctrine of Mental Diseases, he argues that the proximate cause of mania is not seated in the brain itself, but in the meninges, "the increased vascularity of which is relieved either by an appropriate treatment, or by effusions, etc., into the sac of the arachnoid." In the former case, the patient is cured of his malady; but, in the second, the maniacal symptoms are succeeded by dementia or paralysis; the "phenomena", to quote the words of Bayle, "usually dependent on compression of the brain." Bayle writes thus: "The cessation or diminution of maniacal violence, the great loss of power observed in the intellectual faculties, and the commencement of general paralysis which takes place at the transition into the last period of the disease, result from compression of the brain, owing to the exhalation of serosity into the cavity of the arachnoid, the serous infiltration of the pia mater, and an effusion of the same kind into the lateral ventricles. . . The progress of paralysis and dementia indicates a corresponding increase of cerebral compression." The views of Calmeil-a writer of equal reputation with Bayle, if not of greater, and enjoying the same amount of experience and opportunity of solving the various difficulties in the way of necroscopical research-are widely dissimilar and contradictory. The tables will prove to you the frequency with which the grey or cortical substance is affected with disease, i.e., disorganised; and, in so far as numerical proportions are concerned, this structure is seen to rank next to the meninges, so called by Bayle. Calmeil then insists on it that mania is the direct effect of inflammation of the cortical substance of the brain, which, if not remedied, leads to a want of cohesion in the grey substance, the discoloration of which is a peculiar phenomenon. Calmeil, moreover, considers that the general paralysis of the insane is the inevitable sequence of such a state of things; and his reasons for rejecting the opinions of Bayle are thus summed up. " 1 . He has observed that serosity in the great cavity of the arachnoid is wanting in some strongly marked instances of the disease. 2. He has frequently discovered similar effusions in the heads of individuals who had perished under dementia, without any symptom of paralysis even to the last. 3. In cases in which effusions were found of five or six ounces of serosity, the symptoms of general paralysis had been not less intense than in others displaying effusions of twice that extent. 4. If the compression of the brain were 20 coaniderable as many have thought, the structure of its parts would display disorganisation of some kind; but the structure of the convolutions, commissures, septum, etc., is uninjured. 5. In cases of chronic hydrocephalus of long duration, the deposit of serosity has been enormous, without loss of locomotive power, till the disorder reached its last degree. 6. If compression from such a cause acted mochanically, we should expect paralysis depending on it to affect all nerves equally or indifferently; no reason could be perceived why the motive faculty should be impaired first in the tongue, then in the muscles of the lower members, and lastly in the upper, as the fact is observed to be in general paralysis. 7. We certainly cannot imagine that, such a cause acting, the upper extremities would still retain their mobility unimpaired; after the total palsy of the lower limbs." For these and other reasons, M. Calmeil concludes that "the symptoms of mania, or rather of dementia, or of general paralysis, are not, as M. Bayle supposed, dependent on compression of the brain, the result of effusion, but on the state of the encephalon, which gives rise to such effusion, and chiefly to inflammation, of which the thickenings, adhesions, and vascular turgescence of the pia mater, and the peculiar condition of the cineritious substance, otherwise afford sufficient proof.

On proceeding with our inquiries into this interesting department of pathology, we learn that Foville is the authox of opinions which differ widely from not only those mentioned by Bayle, but also from the conclusions of Calmeil, just quoted. Foville, like Calmeil, attaches the greateat importance to the post mortem appearances of the cortical substance of the brain. In fact, these physicians claim for this particular structure a parallel importance to the insisted on by Bayle for the meninges, as he prefers to dosignate the membranes of the brain; but, whilst doing so, it is not a little strange that the first named should connect with mental derangement (mania) those specific appearances, which the latter regards as restricted to general paralysis. When treating of the changes in the grey substance, Foville has these words: "In the most acute cases, the surface of the cortical portion presents, on the removal of the membranes, a most intense redness, approaching to that of erysipelas. This is still more marked in the substance of the grey matter itself; it is more striking in the frontal regions than in the temporal lobes, and in the higher regions than in the posterior lobes of the brain." In briaf terms, the morbid changes observed by Foville in acute cases of madness are nearly confined to the following, viz.: " Red colour, uniform, and very intense; numerous mottled spots, varying from a bright to a violet rod, bloody points, minute extravasations of blood, diminished consistence in the thickness of the cortical substance, coincidents mostly with a slight increase of consistence in its surface, dilatation of the ressels, resistance of their parietes."

But there seems no end to the disagreements of our continental friends. Those of my hearers who may not hare given their attention to this department of medical ecience, will be not a little astonished to learn that Foville has 
frend jet another anee for the genemal paraljois of the frane- one located not in the meninges, as Bayle teaches es, nor in the cortical substance of the brain, as Calmeil acearts, but in the medullary (fibrous) or white substance of the cerebral mass. This, he sajs, is indurated in all caces of mania, complicated with general paralysis. "Each cenebral fibre has contracted morbid adhesions with the currounding fibres, 20 as to render their separation imposaivle." Buch are his words.

Drs. Prichard and Hitchman, and Mr. Solly, advocate a very similar doctrine to that insisted on by Foville, in so far as the changes in the grey or cortical substance are concerned. Thus, the first named has given it as his opinion, that a softness of the cortical substance belongs to cases of the last degree of dementia, with general paralysis; and that, in all such cases, its colour is more brown than usual. The second writer insists, and very properly 80, that inanity is essentially dependent upon " some change or irritation produced in the vesicular neurine of the convolutions of the brain; and that that malady is influenced by the ame laws, and dependent on like physical changes of material structure, as are diseases of the lungs or any other viscera." He adds, moreover, "that in every case of acute othenic manis there is an inflamed condition of that structure; and that the convolutions, if seen, would present a roseate hue." Mr. Bolly, at p. 400 et seq. of his great work On the Brain, has these words: "We cannot, of course, ascribe the mental disturbance, excitement, excessive pain, intolerance of light, delirium, and insanity, which we have observed as the diagnostic marks of inflammation of the arachnoid and pia mater, to simple lesion of either a serous or rascular membrane, we are compelted to refer them all to the injury which that portion of the brain in contact with those membranes must have reeeived from the disturbance of its circulation. Hence it reasonably follows, that the hemispherical ganglia (brain) are intimately connected with the intellectual powers, and that it is in them peculiarly, and not in the whole cerebral mass, that these powers reside; in fact, as before stated, that the medullary substance benesth is, in all probability, merely the passive servant, as it were, of the cineritious, either as the conductor of its commands to the muscles, or of the materials, namely, the various impressions made on the peripheral extremities of the nerves of sense, which the cineritious perceives, and with which it works."

The reciprocity of action, both normal and abnormal, between the meninges and the cerebral substance is, as Mr. Bolly observes, much insisted on by many eminent men, including Pinel, Bouilland, and Lallemand. The last named writes: "The substance of the brain is irritated by an inflammation of the arachnoid, from its vicinity, and its functions are therefore exalted; and consequently those of the nervous system under its dependence and consequently those also of the muscular system: and from hence arise convulsive movements, etc. But, as the tissue of the brain is not yet destroyed, these symptoms are neither accompanied with nor followed by paralysis." The few following words are from the Principles of Medicine, by Dr. Billing: "But although, upon a careful analysis of the symptoms and the different forms of the neuroses, we may, with attention to physiology, refer some to an affection of the cineritious, and others of the medullary parts of the nervous system, we should, a priori, from our knowledge of the conmexion and mutual cooperation of these two divisions of the nervous system, expect to meet with disease depending upon eimultaneous disturbance in both. Thus, from the violent operation of sedatives, or when an animal is bled to death, the first to suffer is the most vascular-i.e. the seereting and the sensorial part, the cineritious substance; hemee the indistinctness of the perceptions and thoughts, and the weakness of the involuntary and voluntary actions. If the operation of the sedative be increased, or the analogoes injury of further loss of blood take place, the medulwo part of the nervous system evinces its effect by general epenodic muscular contractions."

I lare alreads wtated that, secording to Foville and D
Hitchman, in caces of scute manis, " the grey matter of the brain is found of a most intense redness, approaching to that of erysipelas", or "injected, and of a roseate hue". Mr. Solly, however, is found to declare the same structure to present, and in the same disorder (mania), "a dark plum colour". Further even than this, I have the notes of the post mortem examination of $\mathbf{M}$. A. (a patient of the Hanwell asylum in 1842, and who died there under my care, during a paroxysm of acute mania), in whom Dr. Conolly has roported that " the cineritious substance was generally very. pale".

But for these, and not less the foregoing contradictions, to which I have had occasion to refer, I shall hope, in my next lecture, to offer a most satisfactory explanation; and likewise to render the same the means of demonstrating, in the most conclusive manner, the bond fide nature and seat of mental derangement in all its various phases.

Northwoods, Bristol, August 1855

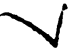

\section{THE MODERN TREATMENT OF} FRACTURES.

By BENJAMIN HUNT, Esq., Surgeon to the General Dispensary, Birmingham; late Resident Surgeon to the Queen's Hospital.

[Concluded from page 701.]

CASE XXX. H. R., aged 25 years, was taken to the Queen's Hospital on the 7th of January, 1853, in consequence of having suffered a comminuted fracture of his right leg, with a lacerated wound of the integument, from the wheel of 2 fire-engine passing over it.

I did not see the patient until the 22nd of February, six weeks after the receipt of the injury. The condition of the limb was then as follows: the tibia was broken obliquely from above downwards, and behind forwards; about an inch of the lower extremity of the upper fragment projected through a wound in the integument, and was necrosed; the leg was much shortened and deformed, being bowed anteriorly, and the heel depressed, viewed laterally; the wound was on the inner and anterior surface, about four inches above the ankle; it discharged pus in large quantities, and the parts about were much thickened.

The patient himself had suffered very much from pain, and wore an anxious expression on his face. The treatment that had been adopted consisted in supporting the foot and leg by well padded lateral splints, which reached to the knee; but they were inadequate for their purpose; every movement the man made allowed the fragments to ride one upon the other, causing pain, and keeping up irritation. To obviate these drawbacks to union, the limb was placed upon M'Intyre's splint, and kept carefully bandaged to it for three weeks, with much ease to the patient, and affording facility of dressing the wound; but, at the expiration of this period, the man complained of his back becoming sore, and also of the heel: symptoms of hectic began to show themselres, so that fear of sinking, from long confinement to bed, was entertained. Amputation of the limb seemed to be almost the only procedure by which his life could be saved.

Under these circumstances, I applied the apparatus so as to include the foot, leg, and half the thigh, in an extended position, as one mass ; and, on the following day, I made an opening in the case opposite the wound, for the escape of pus, and the employment of dressings; the object being to afford a complete support to the broken leg, so that he might leave his bed, and benefit by the change of posture, without disturbance to the fractured ends of the bone. In this I did not succeed in the first instance, because of the weakness of the apparatus, which did not give sufficient support to the limb. At the expiration of a week, therefore, the apparatus was reapplied with greater care, and so efficiently that he left his bed on the recond day after it application to $8^{\circ}$ on erutches; and from that tines the 